\title{
Tecnologias digitais na formação de professores de Língua Portuguesa: uma proposta didático-pedagógica à luz da Base Nacional Comum Curricular
}

\author{
Elizabeth Freitas B. da Silva Paes ${ }^{1}$, Gilmara T. Barcelos ${ }^{1}$, Analice de O. Martins ${ }^{1}$ \\ ${ }^{1}$ Instituto Federal de Educação, Ciência e Tecnologia Fluminense (IFFluminense) \\ CEP: 28030-130 - Campos dos Goytacazes - RJ - Brasil \\ epaes@iff.edu.br, gilmaratbp@gmail.com, analice.martins@terra.com.br
}

\begin{abstract}
In view of the changes established by the Common National Curricular Base and by Resolution No2, of December 20, 2019, it is important to rethink teaching practices that consider the pedagogical use of digital technologies and are in convergence with current legislation. In this context, a qualitative research was carried out throught a pedagogical intervention. Therefore, the article aims to present the perception of undergraduate studentss in Letters, about a didactic-pedagogical proposal that was tried with them. The data collection instruments were observation, activity responses and questionnaire. It was found that such a proposal brought contributions to the training of future teachers of the course.
\end{abstract}

Resumo. Diante das mudanças estabelecidas pela Base Nacional Comum Curricular e pela Resolução $N^{\circ}$. 2, de 20 de dezembro de $2019^{1}$, é importante repensar práticas docentes que considerem o uso pedagógico das tecnologias digitais e estejam em convergência com a legislação vigente. Neste contexto, foi realizada uma pesquisa qualitativa por meio de uma intervenção pedagógica. Sendo assim, o artigo visa apresentar a percepção dos licenciandos em Letras, sobre uma proposta didático-pedagógica que foi experimentada com eles. Os instrumentos de coleta de dados foram observação, respostas das atividades e questionário. Constatou-se que tal proposta trouxe contribuições para a formação dos futuros docentes do curso.

\section{Introdução}

A partir da disseminação do uso das tecnologias digitais (TD), que trouxe impactos consideráveis em diversas áreas da sociedade, inclusive na escola, pesquisas apontam sobre a necessidade em se repensar as práticas pedagógicas [Diesel et al. 2017, Gentilini e Scarlatto 2015, Kenski 2012]. Isso se torna iminente diante da recente homologação de documentos oficiais que definem diretrizes para educação brasileira, dentre os quais a Base Nacional Comum Curricular (BNCC), [Brasil 2018], as Diretrizes Curriculares Nacionais para a Formação Inicial de Professores da Educação Básica e a Base Nacional Comum para a Formação Inicial de Professores da Educação Básica (BNC - Formação)

\footnotetext{
${ }^{1}$ Define as Diretrizes Curriculares Nacionais para a Formação Inicial de Professores para a Educação Básica e institui a Base Nacional Comum para a Formação Inicial de Professores da Educação Básica (BNC-Formação).
} 
[Brasil 2019] e por outro lado, a ainda tímida utilização das tecnologias digitais (TD) por parte dos professores [Ribeiro 2018]. Sendo assim, faz-se necessário o desenvolvimento de práticas pedagógicas que considerem essa abordagem, especialmente na formação de professores.

As referidas Diretrizes e a BNC-Formação [Brasil 2019] estabelecem que seja demandado aos licenciandos o desenvolvimento das competências gerais docentes com base nos mesmos princípios das competências gerais estabelecidas pela BNCC [Brasil 2018], devendo, desta forma, haver uma total consonância entre a formação docente e a Educação Básica. Neste sentido, corrobora Schõn (1990), quando discorre sobre a homologia de processos, que consiste em empregar, na formação de professor, as mesmas metodologias e métodos que poderão ser utilizadas por ele no processo de ensino e aprendizagem de seus alunos. Isso corresponde a um princípio para a formação, cuja aplicação não é direta, mas que pode ser apreendido ao ser ensinado, utilizando e problematizando as mesmas estratégias que se deseja que os alunos aprendam e incorporem em seu cotidiano profissional.

O presente artigo tem por objetivo apresentar os dados de uma pesquisa qualitativa, realizada por meio de uma intervenção pedagógica, em que se evidencia a percepção dos licenciandos em Letras, de um Instituto Federal, sobre uma proposta didático-pedagógica, experimentada com eles e que embasou os dados desta pesquisa. A proposta foi elaborada tendo por princípio os textos multimodais estabelecidos pela BNCC [Brasil 2018] para o ensino de Língua Portuguesa da Educação Básica (anos finais do Ensino Fundamental e Ensino Médio) e ainda a indicação para utilização de TD no processo de ensino e aprendizagem. Pretende-se, dessa forma, trazer contribuições para a formação dos professores de Língua Portuguesa a partir de práticas que envolvam o uso pedagógico das TD, em conformidade com a legislação vigente.

Tendo em vista o objetivo descrito, este artigo encontra-se organizado em quatro seções. Na seção 2, aborda-se a questão da formação dos professores de Língua Portuguesa para o uso das tecnologias digitais. Na seção 3, descrevem-se os procedimentos metodológicos da pesquisa, na seção 4, são apresentados os resultados obtidos por meio da experimentação de uma proposta didático-pedagógica. Por fim, na seção 5, as considerações a respeito deste estudo são destacadas.

\section{Tecnologias digitais e formação dos professores de Língua Portuguesa}

Para Ribeiro (2018), apesar de as TD fazerem parte da vida das pessoas, inclusive dos professores e alunos, essas ainda são pouco utilizadas no meio acadêmico. A autora salienta que as TD podem ser aliadas no processo de ensino e aprendizagem. Coscarelli (2016) complementa destacando que a escola precisa discutir e se apropriar das TD, para que estas sejam incorporadas à vida dos alunos. Neste sentido, destaca-se que as ações de ler e escrever passaram por transformações no decorrer do tempo, especialmente a partir da década de 1990, com a disseminação das TD, em que novas práticas foram consideradas [Ribeiro 2018].

Neste contexto, a BNCC [Brasil 2018] salienta que, muito por conta dessas tecnologias, os textos e discursos da atualidade estruturam-se de forma híbrida e, em muitas semioses, já que diferentes sistemas de signo fazem parte de suas composições [Brasil 2018]. Assim, tal documento estabelece que para o ensino de Língua Portuguesa, 
nos anos finais do Ensino Fundamental e Ensino Médio, sejam considerados as múltiplas linguagens presentes em meio à cultura digital e os novos comportamentos proporcionados por essas linguagens [Brasil 2018]. Sampaio e Oliveira (2017) consideram que muitas das linguagens utilizadas na contemporaneidade envolvem as TD. Essas transformações não são apenas em relação à utilização das tecnologias, mas também ao aspecto linguístico, pois tais modificações afetam diretamente o conteúdo, a forma e a finalidade do que é falado e/ou redigido [Sampaio e Oliveira, 2017].

Para Santaella (2012), é preciso ter consciência que o homem é um ser social, mediado por uma rede complexa e plural de linguagens, em que a comunicação é realizada por meio da leitura, de imagens, gráficos, sons, sinais, expressões, números, dentre outros. De acordo com a autora "[...] existe uma linguagem verbal, linguagem de sons, que traduzidas formam a linguagem escrita, [...] mas existe simultaneamente uma enorme variedade de outras linguagens que também se constituem em sistemas sociais e históricos de representação do mundo" Santaella (2012, p.16). É importante, portanto, preparar os professores, especialmente os de Língua Portuguesa, para explorar com seus alunos as diversas linguagens presentes no cotidiano, para que sejam considerados "[...] a cultura digital, os multiletramentos, os novos letramentos ${ }^{2}$, entre outras denominações que procuram designar novas práticas sociais e de linguagem" Brasil (2018, p. 478).

Diversas pesquisas análogas à realizada [Santos e Teixeira 2019; Ribeiro 2018; Nóvoa 2017] apontam que, apesar de as TD terem provocado profundas mudanças na sociedade, elas ainda não foram integradas, de forma efetiva às escolas. Do mesmo modo, Silva e França (2014) destacam a relevância dos licenciandos experimentarem, como alunos, as TD que poderão utilizar em suas futuras práticas docentes. Em paralelo, autores como Rojo (2013) e Coscarelli (2016), abordam a relevância do uso pedagógico das TD no processo de ensino e aprendizagem de LP. Neste sentido, faz-se necessário o desenvolvimento de pesquisas e propostas-didáticos pedagógicas que contemplem o uso das TD.

Foram utilizadas ainda leituras de trabalhos relacionados ao tema como as obras dos autores Paiva (2016), Campos e Matuda (2019), Nichele, Schlemer e Ramos (2015), Fettermann e Tamaris (2019.

\section{Metodologia}

A presente pesquisa ${ }^{3}$ apoia-se numa abordagem qualitativa e faz parte de uma pesquisa de dissertação do Programa de Mestrado Profissional em Ensino e suas Tecnologias. Para tanto, foi realizada uma intervenção pedagógica, no âmbito de um componente curricular, do Curso de Licenciatura em Letras, de um Instituto Federal. Nessa intervenção, uma proposta didático-pedagógica foi experimentada com sete alunos do referido Curso, no final do $2^{\circ}$. semestre letivo de 2019, em dez encontros, com carga

\footnotetext{
2“As práticas de leitura e produção de textos que são construídas a partir de diferentes linguagens ou semioses são consideradas práticas de multiletramentos, na medida em que exigem letramentos em diversas linguagens, como as visuais, as sonoras, as verbais e as corporais. Já os novos letramentos remetem a um conjunto de práticas específicas da mídia digital que operam a partir de uma nova modalidade [...].“ [Brasil 2018, p. 478].

3 A pesquisa foi submetida e aprovada pelo Conselho de Ética em Pesquisa (CEP), registrada na Plataforma Brasil - CAEE 30831120.0.0000.5268, Parecer 4.007.645.
} 
horária total de $20 \mathrm{~h}$ /aulas). Essa proposta aborda o uso pedagógico das TD na formação dos professores de Língua Portuguesa da Educação Básica (anos finais do Ensino Fundamental e Ensino Médio), levando-se em consideração os textos multimodais, práticas de leituras não lineares e a disseminação de notícias falsas, tendo como parâmetro a BNCC [Brasil 2018] e as Diretrizes Curriculares Nacionais para Formação Inicial de Professores para a Educação Básica e a BNC-Formação [Brasil 2019].

A proposta foi constituída por seis módulos, a saber: i) O Ensino de Língua Portuguesa no contexto da BNCC e da Multimodalidade; ii) Memes; iii) Infográficos; iv) Fake News e Podcast; v) Hiperlinks e o uso pedagógico do QR Code e vi) Fanfics. Para sua experimentação, foi criado um curso no ambiente virtual de aprendizagem (AVA) Schoology. Todos os encontros foram realizados no laboratório de informática da Instituição em que os alunos fazem o curso e foram utilizados computadores e tablets para experimentação das TD. As atividades propostas (Quadro 1) possibilitaram o desenvolvimento da autonomia, da criatividade e do protagonismo dos alunos. Como instrumento de coleta de dados, além da observação, foi utilizado um questionário e também análise das respostas das atividades e das interações ocorridas no AVA.

Quadro 1. Relação das atividades propostas e recursos digitais utilizados ${ }^{4}$

\begin{tabular}{|c|c|c|c|}
\hline Módulo & Atividades propostas & $\begin{array}{l}\text { Recursos } \\
\text { utilizados }\end{array}$ & Link para download \\
\hline II & $\begin{array}{l}\text { Leitura e produção de } \\
\text { memes }^{5}\end{array}$ & $\begin{array}{l}\text { Aplicativo Meme } \\
\text { Generaton Free }\end{array}$ & $\begin{array}{c}\frac{\text { https://play.google.com/store/apps/det }}{\text { ails?id=com.zombodroid.MemeGener }} \\
\text { ator }\end{array}$ \\
\hline III & $\begin{array}{l}\text { Elaboração de } \\
\text { infográficos }\end{array}$ & Plataforma Canva & https://www.canva.com/pt_br/ \\
\hline III & Enquete & Poll EveryWhere & $\begin{array}{c}\text { https://play.google.com/store/apps/det } \\
\text { ails?id=com.polleverywhere.mobile }\end{array}$ \\
\hline IV & $\begin{array}{l}\text { Criação de podcast } \\
\text { (edição e gravação de } \\
\text { audios) e fake News }\end{array}$ & Aplicativo Anchor & $\begin{array}{c}\text { https://play.google.com/store/apps/det } \\
\text { ails?id=fm.anchor.android }\end{array}$ \\
\hline V & $\begin{array}{c}\text { Criação e Leitura de } Q R \\
\text { Codes }^{8}\end{array}$ & $\begin{array}{l}\text { Gerador de códigos } \\
\text { QR Code Monkey } \\
\text { (Criação) QR Code } \\
\text { Reader (Leitura) }\end{array}$ & $\begin{array}{l}\underline{\text { https://www.qrcode-monkey.com/ }} \\
\text { https://play.google.com/store/apps/det } \\
\text { ails?id=com.mobile.qrcodereader }\end{array}$ \\
\hline VI & $\begin{array}{l}\text { Fanfics }^{9} \text { (produção, } \\
\text { compartilhamento e } \\
\text { interação) }\end{array}$ & AVA Schoology & https://www.schoology.com/ \\
\hline
\end{tabular}

Fonte: Protocolo de pesquisa.

\footnotetext{
${ }^{5}$ Os memes são formados por um hibridismo de palavras e imagens e apresentam expressões ideológicas plurais, quase sempre em caráter satírico [Santos 2020].

${ }^{6}$ Infográfico "[...] é um exemplo de texto construído na multimodalidade, concebido por diferentes modos semióticos, sobretudo o verbal e o imagético" [Paiva 2016, p. 45].

7 Podcast têm sido utilizados com freqüência pelas mídias digitais de telejornalismo e apresenta potencialidade no processo de ensino e aprendizagem [Campos e Matuda 2019].

8 QR Codes "[...] são códigos de barras bidimensionais, que podem ser rapidamente convertidos em informação, por estarem associados a um texto interativo, um link da internet, uma localização geográfica, entre tantas outras possibilidades” [Nichele, Schlemer e Ramos 2015, p. 3].

${ }^{9}$ Fanfics são narrativas elaboradas por fãs de personagens ou obras, séries, filmes, história em quadrinhos, músicas e outros, sem que haja interesse em comercialização dos textos ou desrespeito os direitos autorais [Fettermann e Tamaris 2019].
} 
Cabe salientar que antes da realização das atividades, os temas eram discutidos a partir da apresentação dialogada de exemplos. Ao final do modulo III, o Poll EveryWhere foi utilizado na realização de uma enquete, que teve como objetivo investigar a percepção dos licenciandos sobre os temas abordados nos últimos módulos, memes e infográficos. Um exemplo de sua utilização será apresentado na seção "Resultados e discussões".

Para elaboração dos memes, infográficos e fanfics estabeleceu-se apenas que deveriam contemplar temas que pudessem ser abordados com alunos da Educação Básica (anos finais do Ensino Fundamental e Ensino Médio). Da mesma forma, para a criação dos $Q R$ Codes, o hyperlink deveria ter relação com temas voltados para o ensino de Língua Portuguesa. Já para a elaboração dos podcasts, foram consideradas as fakes news, levando-se em consideração sua relevância neste século XXI. Como a proposta do modulo VI envolvia a produção de fanfics, o compartilhamento e as interações ocorridas entre os alunos, foi utilizado o próprio AVA Schoology, pois este possui características semelhantes às das redes sociais. Após a realização de pesquisas, os alunos fizeram a seleção das obras de seus interesses e elaboraram as fanfics em documento de texto e as compartilharam no AVA. Também foram apresentadas aos alunos as plataformas Nyah! e Wattpad, que são específicas para comunidades que costumam divulgar suas fanfics.

\section{Resultados e Discussões}

Com o objetivo de captar a percepção dos licenciandos sobre a proposta experimentada e verificar se houve contribuição da mesma para sua formação acadêmica e profissional, foi utilizado como instrumento de coleta de dados, o questionário. Este foi respondido pelos licenciandos, após a finalização do ultimo módulo.

A primeira questão buscou identificar a opinião dos licenciandos a respeito da experimentação da proposta didático-pedagógica. Nela, foi utilizada a escala de Likert, que possui como Critério de Avaliação: Concordo (C); Concordo parcialmente (CP); Não concordo nem discordo (NC/ND); Discordo parcialmente (DP); Discordo (D). Os licenciandos deveriam dar suas opiniões sobre assertivas (Tabela 1).

Tabela 1. Percepção dos licenciandos

\begin{tabular}{l|c|c|c|c|c}
\hline \multirow{2}{*}{ Assertivas } & \multicolumn{5}{c}{ Número de marcações recebidas } \\
\cline { 2 - 6 } & C & CP & NC/ND & DP & D \\
\hline As atividades propostas foram inovadoras & 5 & 2 & - & - & - \\
\hline As TD foram abordadas numa perspectiva prática & 6 & 1 & - & - & - \\
\hline $\begin{array}{l}\text { A proposta provocou reflexão em relação ao uso } \\
\text { pedagógico das TD no processo de ensino e } \\
\text { aprendizagem de LP pP }\end{array}$ & & & - & - & - \\
\hline $\begin{array}{l}\text { A partir da proposta, você aprendeu utilizar, } \\
\text { pedagogicamente, os recursos digitais } \\
\text { experimentados }\end{array}$ & & & 2 & & \\
\hline
\end{tabular}

Fonte: Protocolo de pesquisa.

$\mathrm{Na}$ útima assertiva, o licenciando que não concordou, nem discordou, justificou sua resposta, afirmando que não possui recursos em casa e também não dispõe de tempo, sendo assim, esses dois fatores os prejudicam muito, pois ele não consegue praticar o que aprende. De acordo com as respostas, as atividades foram consideradas 
inovadoras e as TD foram abordadas numa perspectiva prática. Tais dados vão ao encontro da abordagem de Imbernón (2016), que salienta que, para se construir uma nova forma de pensar a profissão, é preciso uma cultura que desenvolva um novo processo de formação inicial, de modo que seja mais reflexiva e prática.

Quando questionados se já tinham feito uso dos aplicativos e plataformas experimentados na proposta (Gráfico 1), responderam, majoritariamente, que, com exceção do aplicativo para elaboração de memes, os outros recursos não eram conhecidos antes da experimentação. Diante do exposto, ratifica-se a relevância de os licenciandos conhecerem e experimentarem os recursos digitais para poderem utilizar em suas futuras práticas pedagógicas. Moran, Masetto e Behrens (2006) destacam que um dos princípios metodológicos norteadores para os professores é fazer a integração entre tecnologias, metodologias e atividades pedagógicas.

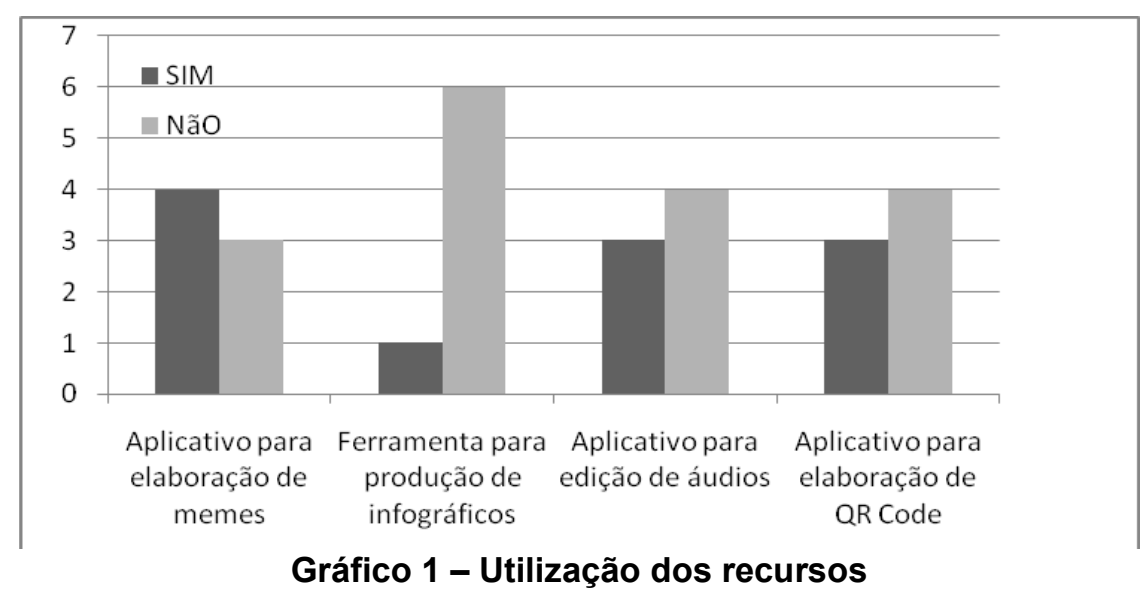

Para fins de identificação, os participantes foram nomeados como: L1, L2... L7. O Quadro 2 apresenta o relato dos licenciandos em relação à experiência no uso desses recursos digitais. Os licenciandos julgaram a experiência como relevante, já que tiveram a chance de conhecer e experimentar recursos digitais, que poderão ser utilizados por eles em suas futuras práticas profissionais. Considera-se que, ao terem contato em sua formação com práticas pedagógicas que possibilitam o uso das TD, os licenciandos são instigados as utilizarem com seus alunos, em sua atuação docente, conforme ratifica Schõn (1990), em homologia de processos.

Quadro 2. Relato dos licenciandos sobre o uso dos recursos digitais

\begin{tabular}{|c|c|}
\hline Aluno & Resposta \\
\hline L1 & $\begin{array}{l}\text { Foi bastante gratificante e inovador o contato que tive ao longo da experimentação. } \\
\text { Aprendi a usar novas tecnologias com finalidade educacional. }\end{array}$ \\
\hline $\mathrm{L} 2$ & A experiência foi muito construtiva, desenvolvi atividades muito interessantes. \\
\hline L3 & Foi uma experiência produtiva, que proporcionou uma nova visão na metodologia. \\
\hline L4 & A experiência foi bem informativa e didática. \\
\hline L5 & $\begin{array}{l}\text { Foi uma experiência enriquecedora, é sempre muito interessante aprender novas } \\
\text { ferramentas digitais. }\end{array}$ \\
\hline L6 & A experiência nos possibilitou um novo leque de recursos para se utilizar com os alunos. \\
\hline L7 & $\begin{array}{l}\text { Foi uma experiência inovadora e divertida. Acredito que se não fossem pelas aulas, eu não } \\
\text { teria contato tão próximo com esses recursos. Eu pretendo utilizá-los futuramente na } \\
\text { minha prática docente. }\end{array}$ \\
\hline
\end{tabular}

Fonte: Protocolo de pesquisa.

Ao final do modulo III, conforme descrito na seção de procedimentos 
metodológicos, foi utilizada a plataforma Poll EveryWhere, que possibilita que as respostas dos participantes apareçam na tela de apresentação, em tempo real, em diversos formatos, como o de nuvem de palavras, por exemplo. A plataforma foi utilizada com o objetivo de promover a enquete e também apresentar e experimentar outro recurso digital. Uma das perguntas da enquete buscou investigar a opinião dos licenciandos em relação ao aprendizado com a leitura e a produção de memes. Dentre as palavras que formaram a nuvem, destacam-se: interessante, diferenciado, estimulante, moderno e criativo. Os comentários indicam que a abordagem sobre memes foi considerada relevante e atual para os licenciandos; isso é bastante significativo, visto que a BNCC [Brasil 2018] salienta sobre a relavância em se desenvolver práticas de linguagem do meio digital como forma de ampliar a construção de sentidos.

Quando perguntados se, antes da experimentação da proposta didáticopedagógica, já tinham utilizado, pedagogicamente, os dispositivos móveis para realizar alguma atividade, dos sete licenciandos, três afirmaram que nunca realizaram nenhum tipo de atividade pedagógica com dispositivos móveis. Dois afirmaram que utilizaram o aplicativo Kahoot na aula de outro componente curricular e outros dois disseram que já utilizaram, mas não especificaram o uso ora proposto. Desta forma, as respostas sinalizaram que os dispositivos móveis foram usados de forma incipiente por alguns e que outros nem chegaram a fazer uso desses dispositivos em suas práticas escolares. Para Moran (2013), as tecnologias móveis são desafiantes, uma vez que possibilitam que os processos de gestão do conhecimento sejam descentralizados, já que a aprendizagem pode ocorrer em qualquer lugar e de diferentes modos. Assim, ensinar e aprender podem ocorrer de modo mais flexível, ativo e personalizado.

Em relação à utilização das $\mathrm{TD}$, enquanto professores, os licenciandos podiam escolher mais de uma alternativa, dentre os quatro que foram utilizados na experimentação da proposta didático-pedagógica (Quadro 3). própria.

Quadro 3-Recursos digitais que os licenciandos pretendem utilizar

\begin{tabular}{|l|l|}
\hline \multicolumn{1}{|c|}{ Recursos } & \multicolumn{1}{c|}{ Marcações recebidas } \\
\hline Aplicativo para elaboração de memes & L1; L2; L3; L4; L6; L7 \\
\hline Ferramenta para produção de infográficos & L2; L3; L4; L5; L6; L7 \\
\hline Aplicativo para criação e edição de podcasts & L2; L5; L6; L7 \\
\hline Aplicativo para leitura e produção de QR Codes & L1; L3; L4; L5; L6; L7 \\
\hline
\end{tabular}

Fonte: Elaboração própria.

Conforme os dados coletados, os licenciandos pretendem utilizar todos os recursos que foram experimentados na proposta didático-pedagógica. As respostas sinalizam que os recursos foram bem aceitos por eles. Para Santos (2020), com a circulação das transmídias, multimídias e hipermídias no ciberespaço, as narrativas se apresentam imagéticas, sonoras, audiovisuais e textuais, assim como os temas abordados, dentre os quais: memes, infográficos e podcasts. O Quadro 4 apresenta a justificafiva dada pelos licenciandos para escolha dos recursos informados.

\section{Quadro 4 - Justificativa pela escolha dos recursos digitais}

\begin{tabular}{|c|l|}
\hline Aluno & \multicolumn{1}{c|}{ Resposta } \\
\hline L1 & Pois dialogam mais com a realidade dos alunos, além de serem interativos. \\
\hline L2 & $\begin{array}{l}\text { Acredito que sejam recursos interativos e que possibilitam trabalhar temas que têm } \\
\text { relação com a minha área de atuação. }\end{array}$ \\
\hline
\end{tabular}




\begin{tabular}{|c|l|}
\hline L3 & Foram os que mais gostei. \\
\hline L4 & $\begin{array}{l}\text { Escolhi os recursos que, em minha visão, mais liberdade de criação oferecem ao aluno } \\
\text { e ao mesmo tempo os mais simples de desenvolver. }\end{array}$ \\
\hline L5 & Porque são ferramentas úteis nas atividades pedagógicas no tempo de hoje. \\
\hline L6 & $\begin{array}{l}\text { Ao meu ver tornaria o ambiente escolar mais interativo, visto que os alunos são da } \\
\text { geração z. Provavelmente haveria um mais produtivo. }\end{array}$ \\
\hline L7 & $\begin{array}{l}\text { Utilizaria todos os recursos, pois acredito que cada um possui possibilidades distintas } \\
\text { na elaboração de exercícios construtivos e estimulantes para os alunos. }\end{array}$ \\
\hline
\end{tabular}

Fonte: Elaboração própria.

Os licenciandos reconheceram que os recursos digitais utilizados são adequados às propostas pedagógicas desse novo contexto educacional, além de promoverem interação e se aproximarem da realidade dos alunos, especialmente os que nasceram imersos nas tecnologias. Conforme salientam Bacich; Moran (2018), a educação deve ser reinventada. Para tal, é necessário analisar o lado positivo e negativo, além das alterações vindas da interação com a cultura digital, da inserção das TD, dos recursos e das linguagens utilizadas pelas mídias aliadas à prática pedagógica.

Em relação à proposta experimentada, procurou-se verificar se a mesma trouxe contribuição para a formação acadêmica e profissional dos licenciandos (Quadro 5). De acordo com os relatos positivos dos licenciandos, considera-se que a proposta didáticopedagógica trouxe contribuição para a sua formação acadêmica e profissional. Conforme relatos, muitos dos recursos utilizados não eram conhecidos pelos licenciandos, então a proposta lhes possibilitou não só apresentação de plataformas e aplicativos com finalidades diversas, mas também a experimentação desses instrumentos e a produção de memes, infográficos, podcasts e QR Codes, que até então não tinham sido abordados desta forma. Os licenciandos julgaram a proposta como inovadora e relatatam que as TD foram utilizadas numa perspectiva prática. De maneira geral, as respostas deles vão ao encontro da finalidade da proposta didático-pedagógica de possibilitar novas aprendizagens aos licenciandos, que poderão ser desenvolvidas com seus futuros alunos, tal qual a homologia de processos.

Quadro 5. Relato dos licenciandos sobre a contribuição ou não da proposta

\begin{tabular}{|c|c|}
\hline Aluno & Resposta \\
\hline L1 & Com certeza sim, já que foi através dela que aprendi outras novas ferramentas \\
\hline L2 & $\begin{array}{l}\text { Sim, pois desenvolvi atividades que eu não conhecia as etapas de constituição, como por } \\
\text { exemplo o podcast, que eu conheci e nunca tinha desenvolvido um. }\end{array}$ \\
\hline L3 & Sim, pois as atividades poderão ser utilizadas na aplicação de conteúdos didáticos. \\
\hline L4 & $\begin{array}{l}\text { Sim, pois apresentou, diversas formas de tornar uma aula mais dinâmcia e assim, eu vou } \\
\text { poder aproveitar o aprendizado com meus alunos. }\end{array}$ \\
\hline L5 & Sim, só vou precisar treinar mais para poder utilizar com meus alunos. \\
\hline L6 & Sim, me trouxe uma nova experiência para aplicação e utilização na prática pedagógica. \\
\hline L7 & $\begin{array}{l}\text { Com certeza, pois enquanto professores devemos ser pesquisadores, buscar sempre novas } \\
\text { possibilidades didático-pedagógicas no exercício de nossa docência e a tecnologia também } \\
\text { faz parte desse exercício. Portanto, essa experimentação foi de extrema importância para } \\
\text { mim. }\end{array}$ \\
\hline
\end{tabular}

Fonte: Elaboração própria.

\section{Considerações Finais}

Após a análise dos dados, constatou-se que as TD são pouco experimentadas nas práticas pedagógicas, principalmente levando-se em consideração a perspectiva prática, 
em que são utilizados aplicativos, softwares, plataformas digitais, objetos de aprendizagem. Principalmente, após a homologação da BNCC (Brasil 2018), essa abordagem é primordial, especialmente, na formação de professores, já que os licenciandos irão desenvolver suas práticas docentes com os alunos da Educação Básica e, desta forma, precisam conhecer e experimentar as TD. Ressalta-se que os recursos digitais utilizados nas atividades da proposta são possibidades a serem exploradas até mesmo por professores de outros componentes, visto que memes, infográficos, qr codes e podcasts podem ser considerados na abordagem de diversos conteúdos.

Destaca-se que, para o planejamento de atividades que envolvem o uso das TD, deve-se levar em conta que a interação e colaboração são essenciais para o êxito dos alunos. No que diz respeito à experimentação da proposta didático-pedagógica, dos sete participantes, um aluno apresentou dificuldade desde o início. Tal situação foi resolvida graças à interação ocorrida durante as atividades.

Para trabalhos futuros, sugere-se edição e gravação de vídeos, que poderia envolver, por exemplo, a produção de paródias. Para tal, há diversos aplicativos, dentre os quais: InShot, Quick, VivaVideo, KineMaster. Propõe-se ainda o uso de jogos digitais no ensino de Língua Portuguesa e recomenda-se que as atividades propostas sejam experimentadas por um numero maior de licenciandos e professores. Espera-se que a pesquisa descrita possa trazer contribuições para práticas docentes que considerem o uso das TD como aliadas ao processo de ensino e aprendizagem.

\section{Referências}

Bacich, L; Moran, J. (2018) "Metodologias ativas para uma educação inovadora: uma abordagem teórico-prática”. Porto Alegre: Penso, 2018.

Brasil (2018). Ministério da Educação. Conselho Nacional de Educação. "Base Nacional Comum Curricular”. Disponível em: http://basenacionalcomum.mec.gov.br/

Brasil (2019). Conselho Nacional de Educação. "Resolução CNE/CP No 2, de 20 de dezembro de 2019". Brasília: Define as Diretrizes Curriculares Nacionais para a Formação Inicial de Professores para a Educação Básica e Base Nacional Comum para a Formação Inicial de Professores da Educação Básica (BNC - Formação). MEC, 2019.

Campos, V. H. M.; Matuda, F. G. (2019) "Uso de podcasts como potencializador do desenvolvimento de gêneros orais de língua portuguesa no ensino médio". Revista: EaD \& Tecnologias Digitais em Educação, Dourados, MS - v. 7, n. 9, p. 85-96.

Coscarelli, C. V. (org.). (2016) “Tecnologias para aprender”. São Paulo: Parábola Editorial.

Diesel, A.; Baldez, A. L. S.; Martins, S. N. (2017) "Os princípios das metodologias ativas de ensino: uma abordagem teórica”. Revista Thema, v. 14, n. 1, p. 268-288.

Fetterman, J. V.; Tamariz, A. D. R. (2019) Práticas contemporâneas de linguagem e produção de fanfics nas aulas de português. In: Benevenuti, C. B.; Rosa, G. L. de; Souza, C. H. M. de. "Leitura e produção de textos multimodais". Campos dos Goytacazes, RJ: Brasil Multicultural.

Gentilini, J.; Scarlatto, E. C. (2015) "Inovações no ensino e na formação continuada de professores: retrocessos, avanços e novas tendências". In: Parente, C. D. da; Valle, L. 
E. L. R. do; Mattos, M. J. V. M. de (org.). A formação de professores e seus desafios frente às mudanças sociais, políticas e tecnológicas. Porto Alegre: Penso.

Imbernón, F. (2016) "Qualidade do ensino e formação do professorado: uma mudança necessária”. São Paulo: Editora Cortez.

Kenski, V. M. (2012) “Tecnologias e ensino presencial e a distância”. 9. ed. Campinas: Papirus.

Morán, J. M. (2013) “Tablets e ultrabooks na educação". Disponível em: $<$ http://www2.eca.usp.br/moran/wp-content/uploads/2013/12/tabletseduc.pdf $>$ Acesso em: 20 maio 2020.

Morán, J; Masetto, M.T.; Behrens, M. (2006) "Novas Tecnologias e Mediação Pedagógica". 6. ed. Campinas, SP: Papirus.

Nichele, A. G.; Schlemmer, E.; Ramos, A. F. (2015) " $Q R$ Codes na Educação em Química”. Renote. Revista Novas Tecnologias na Educação, v. 13, p. 1 - 9.

Nóvoa, A. (2017) Firmar a posição como professor, afirmar a profissão docente. "Cadernos de Pesquisa", v.47 n.166 p.1106-1133 out./dez.

Paiva, F. A. (2016) "Leitura de imagens em infográficos”. In: Coscarelli, C. V (org.). Tecnologias para aprender. São Paulo: Parábola Editorial.

Ribeiro, A. E. (2018) "Escrever, hoje: palavra, imagem e tecnologias digitais na educação”. São Paulo: Parábola.

Rojo, R.H. (2013) “Escol@ Conectada:” Os multiletramentos e as TICS. São Paulo: Parábola.

Sampaio, T. F.; Oliveira, A. S. da. (2017) Produção escrita na era digital: A tecnologia a favor da reescrita e da mediação. "As tecnologias digitais no ensino e aprendizagem de línguas". Juiz de Fora, v.21, n. 1, p. 164-179.

Santaella, L. (2012) “O que é semiótica?” São Paulo: Brasiliense.

Santos, A. dos; Teixeira, A. C. A. (2019) "Formação de Professores e a importância da Fluência Tecnológica Digital em meio ao cenário do Século XXI". Anais do XXV Workshop de Informática na Escola -WIE 2019. Disponível em: https://brie.org/pub/index.php/wie/article/view/8583. Acesso em: 01 jul. 2020.

Santos, E. (2020) "\#lives de maio... Educações em tempo de pandemia". Revista Docência e Cibercultura. Disponível em: https://www.epublicacoes.uerj.br/index.php/re-doc/announcement/view/1109. Acesso em: 01 jul. 2020.

Schõn, D. (1990) “Educating the reflexive practioner". San Francisco: Jossey-Bass.

Silva, A. C. B. da; França, R. S. de. (2014) "Avaliação de software educativo na formação docente: articulando teoria e prática". Anais do XX Workshop de Informática na Escola -WIE 2014. Disponível em: https://www.brie.org/pub/index.php/wie/article/view/3089. Acesso em: 22 set. 2020. 